Check for updates

Cite this: Chem. Commun., 2018, 54, 1323

Received 26th October 2017, Accepted 30th November 2017

DOI: $10.1039 / \mathrm{c} 7 \mathrm{cc} 08024 \mathrm{~g}$

rsc.li/chemcomm

\section{One-pot chemoenzymatic synthesis of trolline and tetrahydroisoquinoline analogues $\dagger$}

\author{
Jianxiong Zhao, ${ }^{a}$ Benjamin R. Lichman, (D) $\ddagger^{\mathrm{b}}$ John M. Ward (D) $^{\mathrm{b}}$ and \\ Helen C. Hailes (D)*a
}

\begin{abstract}
Chemoenzymatic reaction cascades can provide access to chiral compounds from low-cost starting materials in one pot. Here we describe one-pot asymmetric routes to tetrahydroisoquinoline alkaloids (THIAs) using the Pictet-Spenglerase norcoclaurine synthase (NCS) followed by a cyclisation, to give alkaloids with two new heterocyclic rings. These reactions operated with a high atom economy to generate THIAs in high yields.
\end{abstract}

The use of biocatalytic strategies in synthetic applications continues to offer many advantages compared to traditional chemical approaches due to their sustainability, the use of mild reaction conditions and the high levels of stereocontrol that can be achieved. ${ }^{1}$ Biocatalysts that enable $\mathrm{C}-\mathrm{C}$ bond formation are particularly useful and norcoclaurine synthases (NCSs) are of significant interest for the synthesis of tetrahydroisoquinoline alkaloids (THIAs). ${ }^{2}$ THIAs are a large group of secondary metabolites with a range of pharmacological activities including the analgesic morphine, anti-hypertensive magnoflorine, and anti-mycobacterial leucoxine..$^{3-5}$

In plant biosynthetic pathways, NCS catalyses the Pictet-Spengler reaction (PSR) ${ }^{6}$ between dopamine $\mathbf{1}$ and 4-hydroxyphenyl acetaldehyde (4-HPAA) to generate $(S)$-norcoclaurine. ${ }^{7}$ Recently, it has been established that a range of aldehydes, particularly substituted phenylacetaldehydes, and some heteroaromatic and aliphatic substrates, can be accepted by recombinant wildtype (WT) Thalictrum flavum (TfNCS) and Coptis japonica NCS (CjNCS) to generate single-isomer THIAs. ${ }^{8-10}$ NCS has been used in chemoenzymatic cascades, with hypochlorite to produce the aldehyde component. ${ }^{11,12}$ In addition, NCS enzyme cascades

\footnotetext{
${ }^{a}$ Department of Chemistry, University College London, Christopher Ingold Building, 20 Gordon Street, London, WC1H OAJ, UK. E-mail: h.c.hailes@ucl.ac.uk

${ }^{b}$ Department of Biochemical Engineering, University College London, Gower Street, London, WC1E 6BT, UK

$\dagger$ Electronic supplementary information (ESI) available: Experimental details. Preparation of NCS enzymes, reaction details, compound characterization and analytical details. See DOI: 10.1039/c7cc08024g

\# Current address: John Innes Centre, Norwich Research Park, Norwich, NR4 7UH, UK.
}

have incorporated an amine oxidase or transaminases to generate aldehydes: ${ }^{13,14}$ the latter strategy used a second PSR to produce a tetrahydroprotoberberine. ${ }^{14}$ Engineered microbial pathways to natural opioids incorporating NCS have also been described. ${ }^{15,16}$ The reported TfNCS X-ray crystal structure and mechanistic studies, ${ }^{17-19}$ together with the aldehyde promiscuity and recent ketone acceptance, ${ }^{20}$ have highlighted the significant potential of using NCSs more widely.

The alkaloid trolline 2, isolated from the flowers of Trollius chinensis, has been reported to be effective against Staphylococcus aureus and possess antiviral activity. ${ }^{21}$ There are few reported syntheses, however 3 was used in a Bischler-Napieralski strategy to give 2 in $44 \%$ yield (Scheme 1). ${ }^{22}$ Another 3-step approach gave 2 in $73 \%$ yield, however the amine starting material was not

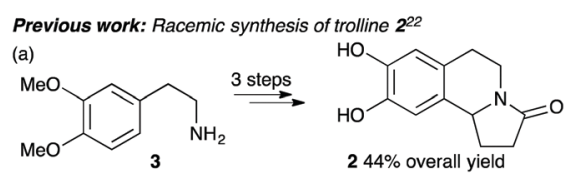

Previous work: Asymmetric synthesis of (S)-trolline [(S)-2 $]^{25}$ (b)<smiles>COc1cc2c(cc1OC)CNCC2</smiles>
This work: Racemic synthesis of trolline 2 and analogues $\mathbf{R}^{1}$ (c)

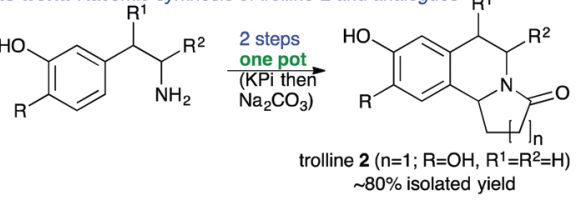

This work: Asymmetric synthesis of (S)-trolline [(S)-2] and analogues

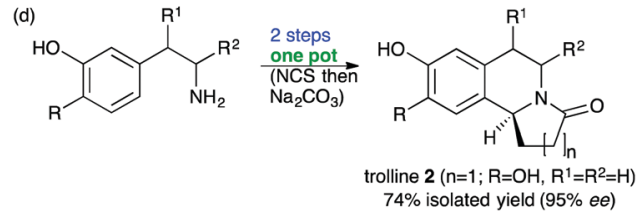

Scheme 1 Previous syntheses of trolline ( $a$ and $b$ ) and the approach used in this work (c and d). 
commercially available. ${ }^{23}$ Multistep asymmetric strategies have been described. One used Jacobsen's catalyst and HCN to establish the C-1 stereochemistry, ${ }^{24}$ while another started with 4 and used the $\left(R, S_{\mathrm{a}}\right)$ - $N$-pinap chiral catalyst to give $(S)-2$ in $41 \%$ yield (5 steps); ${ }^{25}$ strong bases and toxic solvents were also required. $^{25}$

To develop more sustainable rapid routes to these important THIAs, and inspired by the acceptance of non-aromatic aldehydes by NCS, here we describe efficient chemocatalytic cascades to 2 and its analogues in up to $96 \%$ yield and $>99 \%$ ee. One-pot chemoenzymatic cascades offer many advantages, such as avoiding the need for intermediate isolation. ${ }^{26-28}$ Two strategies to trolline 2 were adopted: first a biomimetic phosphate-mediated $\mathrm{PSR}^{29}$ and subsequent cyclisation to establish the one-pot reaction conditions. Secondly, a one-pot NCS-mediated PSR and then cyclisation to give $(S)$-trolline 2 and its analogues. Initial reactions were carried out using $\mathbf{1}$ and commercially available $\mathbf{5}$ under aqueous potassium phosphate (KPi) conditions. ${ }^{29}$ The PSR readily occurred at $\mathrm{pH} 6$ to give a mixture of the linear THIA 6 and, due to spontaneous ring cyclization, 2. A ratio of amine: aldehyde of $1: 1.5$ gave higher yields. A reaction temperature of $60{ }^{\circ} \mathrm{C}$ was optimal; above this, some product decomposition occurred. In addition, as dopamine is oxidatively sensitive, ascorbate was added to avoid side-product formation. ${ }^{20}$ These conditions gave a mixture of linear and cyclised products in a quantitative yield (Table 1 ). It should be noted that the major para-isomer 6 was formed, with some minor ortho-isomer (ratio $15: 1$ ). ${ }^{12}$ The reaction conditions for the cyclisation of linear intermediate 6 were then investigated. Acidic and basic conditions were explored using 6 (para: ortho $15: 1$ ) (ESI; $\nmid$ Fig. S1), and sodium carbonate at $\mathrm{pH} 7.5$ gave the highest yields, $89 \%$, of the lactam. A one-pot procedure was then established with 1 and $\mathbf{5}$ using first step a and then, via the addition of sodium carbonate and adjustment of $\mathrm{pH}$, step $\mathrm{b}$, to give 2 in 97\% yield (para: ortho 18:1) (Table 1). An extraction and purification protocol was developed ${ }^{12,20}$ to avoid the need for chromatographic purification, and rac-2 was isolated in $81 \%$ yield (para:ortho $34: 1$ by HPLC). The one-pot protocol was then applied to aldehyde $7(n=2)$. Notably, more linear THIA 8 was generated in the first step while less cyclized product 9 was formed (and some ortho-product). The formation of lactam 9 was readily achieved upon the addition of sodium carbonate, and isolated (69\% yield, para: ortho $50: 1)$. When aldehyde $10(n=3)$ was used, the linear THIA 11 (72\% yield, para: ortho $7: 1$ ) was formed. No cyclisation to give 12 was observed and $\mathbf{1 1}$ was isolated by preparative HPLC.

The stereoselective approach using NCS was then investigated. Initially, the reaction conditions for the NCS reaction with the novel aldehyde substrates were explored. Using WT- $\Delta 29 T$ NCS (see the ESI $\dagger$ ) and $\mathbf{1}$ and $\mathbf{5}$, the use of acetonitrile and DMSO as co-solvents was investigated as recent work has highlighted several-fold higher product formation with DMSO, perhaps due to enzyme stabilisation effects. ${ }^{20}$ Here DMSO also gave a significantly higher yield ( $\sim 2$-fold increase) compared to acetonitrile after a $3 \mathrm{~h}$ reaction. The extension of the reaction time from $3 \mathrm{~h}$ to $6 \mathrm{~h}$, and the use of 1.5 equiv. of aldehyde, enhanced the combined yield of THIAs to $86 \%$ : no orthoproducts were formed. The yield of 2 formed in step a using NCS was lower than that using KPi, reflecting the lower reaction temperatures used. Furthermore, the amount of DMSO co-solvent could be reduced to $1 \%$ with little effect on the reaction conversion, and this enhanced the ease of product isolation.

Table 1 One-pot routes to rac-2, (S)-trolline 2 and analogues via step a and steps $a+b$

\begin{tabular}{|c|c|c|c|c|c|c|}
\hline & 1 & $\begin{array}{l}5 n=1 \\
7 n=2 \\
10 n=3\end{array}$ & ( $\begin{array}{l}6 n=1 \\
8 n=2 \\
11 n=3\end{array}$ & step b & $\begin{array}{l}2 n=1 \\
9 n=2 \\
12 n=3\end{array}$ & \\
\hline \multirow[b]{2}{*}{ Aldehyde } & \multirow[b]{2}{*}{ Solvent } & \multicolumn{2}{|l|}{$\underline{\text { Step } \mathrm{a}^{a \text { or } f}}$} & \multicolumn{3}{|l|}{ Steps $\mathrm{a}+\mathrm{b}^{b}$} \\
\hline & & $\begin{array}{l}\text { Linear product } \\
\text { yield }^{c}(\text { para: } \text { ortho })\end{array}$ & $\begin{array}{l}\text { Cyclised product } \\
\text { yield }^{c}(\text { para }: \text { ortho })\end{array}$ & $\begin{array}{l}\text { Product yield }{ }^{c} \\
\text { (para }: \text { ortho })\end{array}$ & $\begin{array}{l}\text { Isolated product yield } \\
\text { (para: ortho })\end{array}$ & Product ee ${ }^{h}$ \\
\hline \multicolumn{7}{|c|}{ KPi step $\mathrm{a}^{a}$} \\
\hline 5 & $50 \% \mathrm{CH}_{3} \mathrm{CN} / \mathrm{KPi}$ & $632 \%(15: 1)$ & $268 \%(22: 1)$ & 2 97\% (18:1) & $281 \%(34: 1)^{d}$ & na \\
\hline 7 & $50 \% \mathrm{CH}_{3} \mathrm{CN} / \mathrm{KPi}$ & $875 \%(8: 1)$ & 9 14\% (13:1) & $989 \%(9: 1)$ & $969 \%(50: 1)^{e}$ & na \\
\hline 10 & $50 \% \mathrm{CH}_{3} \mathrm{CN} / \mathrm{KPi}$ & $1172 \%(7: 1)$ & Only 11 & $1172 \%(7: 1)$ & $1126 \%(7: 1)^{e}$ & na \\
\hline \multicolumn{7}{|c|}{ Enzymatic step $\mathrm{a}^{f}$} \\
\hline $5^{g}$ & $10 \% \mathrm{CH}_{3} \mathrm{CN} / \mathrm{HEPES}$ & $635 \%$ & $23 \%$ & na & na & nd \\
\hline $5^{g}$ & 10\% DMSO/HEPES & $661 \%$ & $27 \%$ & na & na & nd \\
\hline 5 & 10\% DMSO/HEPES & $671 \%$ & $215 \%$ & na & na & nd \\
\hline 5 & 1\% DMSO/HEPES & $667 \%$ & $219 \%$ & $275 \%$ & $274 \%{ }^{d}$ & $95 \%$ \\
\hline 7 & 1\% DMSO/HEPES & $882 \%$ & $915 \%$ & 9 96\% & $987 \%^{d}$ & $96 \%$ \\
\hline 10 & 1\% DMSO/HEPES & $1192 \%$ & only 11 & $1192 \%$ & $1163 \%^{e}$ & $>99 \%$ \\
\hline
\end{tabular}

${ }^{a} 1$ and aldehyde $(1: 1.5)$ in KPi buffer $(0.3 \mathrm{M}) / \mathrm{CH}_{3} \mathrm{CN}(1: 1), 18 \mathrm{~h}$, under $\mathrm{Ar}, 60{ }^{\circ} \mathrm{C}, \mathrm{pH}$, and ascorbic acid $\left(1 \mathrm{equiv}\right.$.). ${ }^{b} \mathrm{Na}_{2} \mathrm{CO}_{3}(1 \mathrm{M}), \mathrm{pH}^{7.5}$, and $4 \mathrm{~h}$. ${ }^{c}$ HPLC yields: calculated by analytical HPLC. ${ }^{d}$ Isolated in high purity by a basic and then acidic extraction procedure using EtOAc and then $\mathrm{MeOCO}_{2} \mathrm{Me}^{-}$

${ }^{e}$ Isolated by preparative HPLC. ${ }^{f} \mathbf{1}$ and aldehyde (ratio $\left.1: 1.5\right)$ in co-solvent/HEPES buffer (pH 7.5 and $\left.0.1 \mathrm{M}\right), 37^{\circ} \mathrm{C}, \mathrm{WT}-\mathrm{TfNCS}\left(0.1 \mathrm{mg} \mathrm{mL}^{-1}\right)$, sodium ascorbate (1 equiv.), and 6 h. $^{g}$ As for $f$ but $1: 5$ in a ratio of $1.5: 1$, and 3 h reaction. ${ }^{h}$ The ees determined by chiral HPLC: for trolline the absolute stereochemistry was confirmed by the optical rotation. na, not applicable. nd, not determined. 
Following the reaction conditions established for step b, $(S)-2$ was then formed in the one-pot 2-step chemoenzymatic cascade in $75 \%$ yield, and $95 \%$ ee by chiral HPLC. In a preparative scale reaction, $(S)$-trolline 2 was readily isolated in $74 \%$ yield without the use of chromatographic methods using the extraction protocol developed. Remarkably, although aldehyde $\mathbf{5}$ is structurally quite different from the natural substrate 4-hydroxyphenylacetaldehyde, it was still readily accepted. The extension to aldehyde $7(n=2)$ similarly gave lactam 9 in $96 \%$ yield ( $87 \%$ isolated yield on a preparative scale) and $96 \%$ ee. When using aldehyde $10(n=3)$, the linear THIA 11 was formed in $92 \%$ yield and in very high optical purity ( $>99 \%$ ee) (Table 1 ).

The NCS reaction profiles using WT-TfNCS and aldehydes 5, 7, and $\mathbf{1 0}$ revealed that the bioconversion proceeded more rapidly with the longer chain aldehyde (ESI; $†$ Fig. S2). Computational docking, using the NCS X-ray structure $(5 \mathrm{NON}),{ }^{19}$ of the imine reaction intermediates when using 1 and 5, 7, and 10 was carried out to try and understand this (ESI; $\dagger$ Table S4). Two 'dopamine-first' binding modes were observed, both involving the key interaction between the catechol 3-OH and Lys-122 residues. ${ }^{9,18,19}$ In productive binding modes (Fig. 1A-C), the intermediate occupies a conformation conducive to the subsequent cyclisation step. There were also non-productive binding modes (Fig. 1D-F), with the ester substituent extended into a water channel. The docking experiments suggested that as the aldehyde chain length increases, the productive pose becomes more favourable relative to the non-productive one. For example, docking calculations with $5(n=1)$ identified the non-productive pose (Fig. 1D) to be more favourable than the productive pose (Fig. 1A). By comparison, docking with $10(n=3)$ indicated the productive pose (Fig. 1C) as more favourable than the non-productive one (Fig. 1F). Such alternative favourable binding arrangements of shorter, less sterically demanding aliphatic aldehydes could lower the enzyme efficiency leading to reduced yields. This has implications in other synthetic applications using less sterically challenging aldehydes, and provides insights for future NCS enzyme engineering.

The CjNCS and three variants of $\Delta 29 T f$ NCS (A79I, A79F, and F80L) with modified residues at the active site entrance region $^{9,18,20}$ were also screened against 1 and 5, 7, and 10 (ESI; $\dagger$ Fig. S3 and S4). Similar reaction profiles were observed with WT- $\Delta 297 f$ NCS, although A79F gave slightly higher conversions with 7: a scale-up reaction $(40 \mathrm{~mL})$ generated lactam 9 in $93 \%$ isolated yield and $>99 \%$ ee. The higher ee may reflect steric effects of a more bulky residue on the orientation of intermediates.

The one-pot, 2-step reaction sequence was then extended to dopamine analogues 13-15 using aldehyde 5. In the KPi-mediated reactions, THIAs were readily formed in up to quantitative yields, again containing predominantly para-isomers rac-16-18, with some ortho-product: when using 14, THIAs were formed as a mixture of isomers (see the ESI $\dagger$ ). For WT-TfNCS reactions with 13, $(S)$-16 was formed in 51\% yield as the only regioisomer and 93\% ee (Fig. 2). The bulkier amine metaraminol 14 reacted with 5 in $\mathbf{7 6 \%}$ yield, and gave $(1 S)-\mathbf{1 7}$ (at C-1) as the major isomer (ratio $10: 1$ ) where the minor isomers were a mixture of $(1 R)-\mathbf{1 7}$ (at C-1) and the ortho-product (ratio $\sim 1: 1$ ). The stereochemistry at C-1 was confirmed by $2 \mathrm{D}{ }^{1} \mathrm{H}$ NMR spectroscopy. While higher enzymatic stereoselectivities were observed with metaraminol 14 and phenylacetaldehyde, ${ }^{28}$ here a non-aromatic aldehyde, which can give rise to alternative binding arrangements, led to lower selectivities. When using 15, $(S)$-18 was formed in 57\% yield ( $87 \%$ ee). This is the first time that a fluorinated dopamine

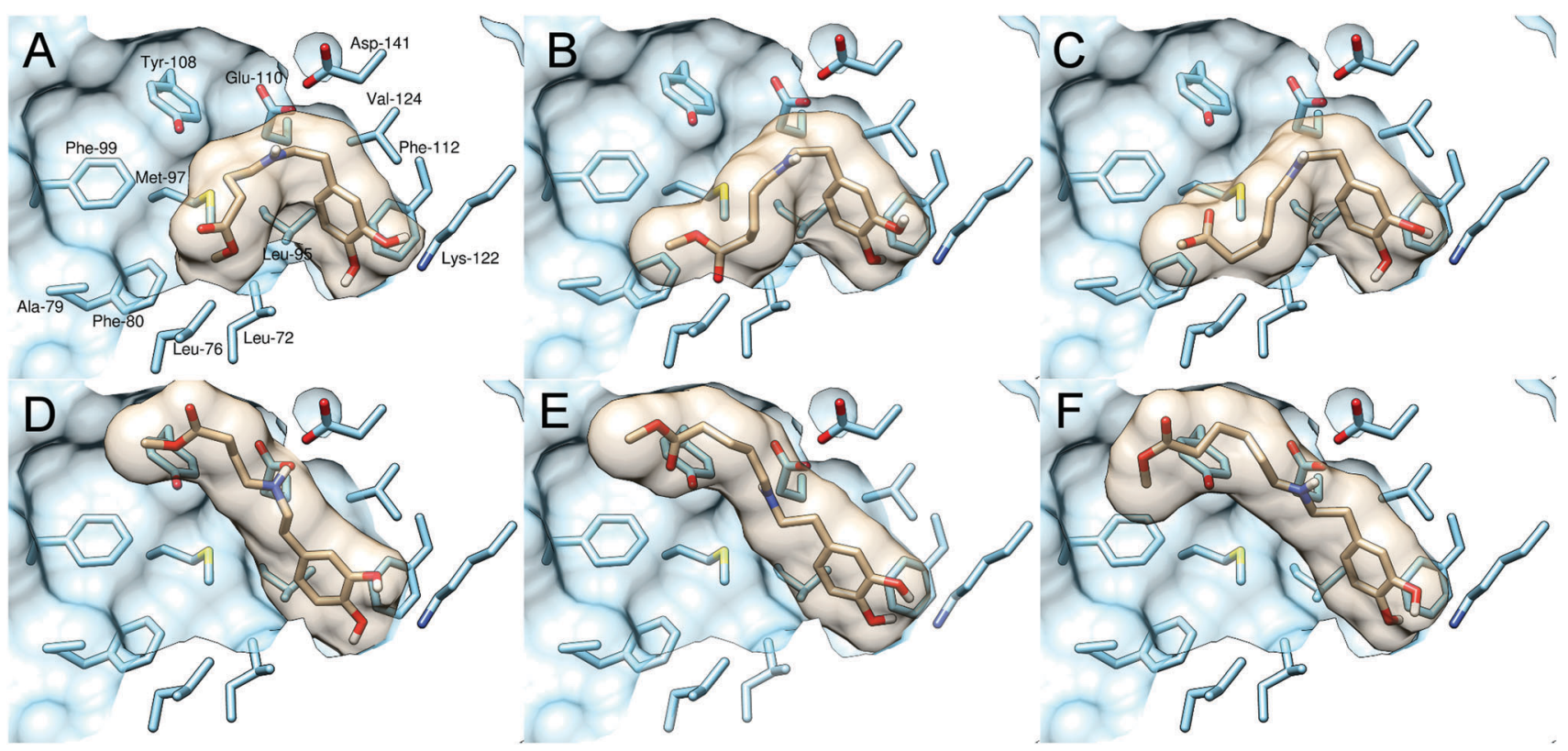

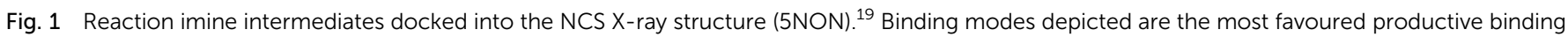

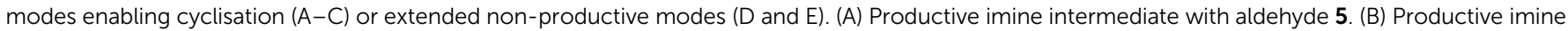

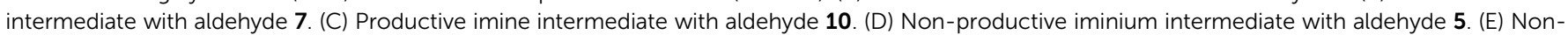
productive iminium intermediate with aldehyde 7. (F) Non-productive iminium intermediate with aldehyde $\mathbf{1 0}$ 
<smiles>NCCc1cccc(O)c1</smiles>

13<smiles>C[C@H](N)[C@H](O)c1cccc(O)c1</smiles>

14

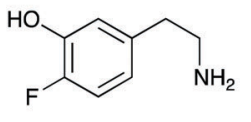

15 step a (NCS) + b to THIAs

HO<smiles>O=C1CC[C@H]2c3ccccc3CCN12</smiles>

(S) $-1651 \%$ yield, $93 \%$ ee<smiles>C[C@H]1[C@H](O)c2cc(O)ccc2[C@@H]2CCC(=O)N21</smiles>

(1S)-17 and isomers in $76 \%$ yield (1S)-17:(1R)-17:ortho, 100:4:6

HO<smiles>O=C1CCC2c3cc(F)c(O)cc3CCN12</smiles>

(S) $-\mathbf{1 8 ~ 5 7 \% ~ 8 7 \% ~ e e ~}$
Fig. 2 THIAs 16-18 prepared using dopamine analogues and the one-pot 2-step cascade.

analogue has successfully been used with NCS to our knowledge. Small-scale reactions were performed to obtain THIAs 16-18 via the one-pot reactions and the products were isolated by preparative HPLC.

Computational modelling of the aminol intermediate with 15 confirmed a similar fit into the active site compared to dopamine (ESI; $\dagger$ Fig. S5). Note that ees were determined by chiral HPLC and the absolute stereochemistry of 16 and 18 was assigned following the established stereoselectivity of the NCS enzymes at C-1 and the correlation to the known stereochemistry of trolline 2 .

Overall, this work highlights the potential of using efficient one-pot chemoenzymatic cascades, not requiring the purification of intermediates, for the rapid stereoselective synthesis of natural and novel alkaloids. It also illustrates the wide substrate tolerance of the NCS enzyme. Furthermore, it demonstrates the application of the sustainable asymmetric catalyst NCS in aqueous media for the synthesis of tricyclic alkaloids.

We gratefully acknowledge UCL (Dean's Prize) and the China Scholarship Council-UCL Joint Research Scholarship for funding to J. Z. and the Wellcome Trust for studentship funding to B. R. L. We also thank K. Karu (UCL Mass Spectrometry Facility) and A. E. Aliev (UCL NMR Facility) of the Department of Chemistry.

\section{Conflicts of interest}

There are no conflicts to declare.

\section{Notes and references}

1 For reviews see: (a) B. M. Nestl, S. C. Hammer, B. A. Nebel and B. Hauer, Angew. Chem., Int. Ed., 2014, 53, 3070; (b) U. T. Bornscheuer, G. W. Huisman, R. J. Kazlauskas, S. Lutz, J. C. Moore and K. Robins,
Nature, 2012, 485, 185; (c) J. H. Schrittwieser and V. Resch, RSC Adv., 2013, 3, 17602.

2 For reviews see: (a) A. Bonamore, M. Barba, B. Botta, A. Boffi and A. Macone, Molecules, 2010, 15, 2070; (b) F. Ghirga, D. Quaglio, P. Ghirga, S. Berardozzi, G. Zappia, B. Botta, M. Mori and I. D’Acquarica, Chirality, 2016, 28, 169.

3 E. Sverrisdóttir, T. M. Lund, A. E. Olesen, A. M. Drewes, L. L. Christrup and M. Kreilgaard, Eur. J. Pharm. Sci., 2015, 74, 45.

4 M. A. Rashid, K. R. Gustafson, Y. Kashman, J. H. Cardellina, J. B. McMahon and M. R. Boyd, Nat. Prod. Lett., 1995, 6, 153.

5 J. D. Guzman, T. Pesnot, D. A. Barrera, H. A. Davies, E. McMahon, D. Evangelopoulos, P. N. Mortazavi, T. Munshi, A. Maitra, E. D. Lamming, R. Angell, M. C. Gershater, J. M. Redmond, D. Needham, J. M. Ward, L. E. Cuca, H. C. Hailes and S. Bhakta, J. Antimicrob. Chemother., 2015, 70, 1691.

6 J. Stöckigt, A. P. Antonchick, F. Wu and H. Waldmann, Angew. Chem., Int. Ed., 2011, 50, 8538.

7 N. Samanani, D. K. Liscombe and P. J. Facchini, Plant J., 2004, 40, 302 .

8 B. M. Ruff, S. Bräse and S. E. O'Connor, Tetrahedron Lett., 2012, 53, 1071.

9 T. Pesnot, M. C. Gershater, J. M. Ward and H. C. Hailes, Adv. Synth. Catal., 2012, 354, 2997.

10 M. Nishihachijo, Y. Hirai, S. Kawano, A. Nishiyama, H. Minami, T. Katayama, Y. Yasohara, F. Sato and H. Kumagai, Biosci., Biotechnol., Biochem., 2014, 78, 701.

11 A. Bonamore, I. Rovardi, F. Gasparrini, P. Baiocco, M. Barba, C. Molinaro, B. Botta, A. Boffi and A. Macone, Green Chem., 2010, 12, 1623.

12 J. J. Maresh, S. O. Crowe, A. A. Ralko, M. D. Aparece, C. M. Murphy, M. Krzeszowiec and M. W. Mullowney, Tetrahedron Lett., 2014, $55,5047$.

13 A. Bonamore, L. Calisti, A. Calcaterra, O. H. Ismail, M. Gargano, I. D'Acquarica, B. Botta, A. Boffi and A. Macone, ChemistrySelect, 2016, 1, 1525.

14 B. R. Lichman, E. D. Lamming, T. Pesnot, J. M. Smith, H. C. Hailes and J. M. Ward, Green Chem., 2015, 17, 852.

15 W. C. DeLoache, Z. N. Russ, L. Narcross, A. M. Gonzales, V. J. Martin and J. E. Dueber, Nat. Chem. Biol., 2015, 11, 465.

16 S. Galanie, K. Thodey, I. J. Trenchard, M. F. Interrante and C. D. Smolke, Science, 2015, 349, 1095.

17 A. Ilari, S. Franceschini, A. Bonamore, F. Arenghi, B. Botta, A. Macone, A. Pasquo, L. Bellucci and A. Boffi, J. Biol. Chem., 2009, 284, 879.

18 B. R. Lichman, M. C. Gershater, E. D. Lamming, T. Pesnot, A. Sula, N. H. Keep, H. C. Hailes and J. M. Ward, FEBS J., 2015, 282, 1137.

19 B. R. Lichman, A. Sula, T. Pesnot, H. C. Hailes, J. M. Ward and N. H. Keep, Biochemistry, 2017, 56, 5274.

20 B. R. Lichman, J. Zhao, H. C. Hailes and J. M. Ward, Nat. Commun., $2017,8,14883$.

21 R. F. Wang, X. W. Yang, C. M. Ma, S. Q. Cai, J. N. Li and Y. Shoyama, Heterocycles, 2004, 63, 1443.

22 L. Moreno, J. Párraga, A. Galán, N. Cabedo, J. Primo and D. Cortes, Bioorg. Med. Chem., 2012, 20, 6589.

23 J. Selvakumar, R. S. Rao, V. Srinivasaptiyan, S. Marutheeswaran and C. R. Ramanathan, Eur. J. Org. Chem., 2015, 2175.

24 T. Kanemitsu, Y. Yamashita, K. Nagata and T. Itoh, Heterocycles, 2007, 74, 199.

25 W. Lin and S. Ma, Org. Chem. Front., 2017, 4, 958.

26 E. Garcia-Junceda, I. Lavendera, D. Rother and J. H. Schrittwieser, J. Mol. Catal. B: Enzym., 2015, 114, 1.

27 H. C. Hailes, P. A. Dalby and J. M. Woodley, J. Chem. Technol. Biotechnol., 2007, 82, 1063.

28 V. Erdmann, B. R. Lichmann, J. Zhao, R. C. Simon, W. Kroutil, J. M. Ward, H. C. Hailes and D. Rother, Angew. Chem., Int. Ed., 2017, 56, 12503.

29 T. Pesnot, M. C. Gershater, J. M. Ward and H. C. Hailes, Chem. Commun., 2011, 47, 3242. 